\title{
Keeping an eye on the many symptoms of COVID-19
}

\author{
Serdar Ozates $^{1}$ (D) Basak Bostanci Ceran ${ }^{1}$ (D)
}

Received: 5 February 2021 / Revised: 5 February 2021 / Accepted: 12 February 2021 / Published online: 24 February 2021

(C) The Author(s), under exclusive licence to Springer-Verlag GmbH, DE part of Springer Nature 2021

Dear Editor,

As of February 2021, coronavirus disease 2019 (COVID19) has been proven to affect the world of ophthalmology in multiple dimensions such as examination, surgery, and treatment processes $[1,2]$. Relatively within a short period, many articles provided information regarding preventive measures during examination and ophthalmological implications of COVID-19 [1]. Hyperemia, epiphora, photophobia, and foreign body sensations were the first reported ocular symptoms and findings associated with COVID-19 [3, 4]. Following reports showed the presence of novel severe acute respiratory syndrome coronavirus (SARS Cov-2) in the ocular surface and revealed the direct link of COVID-19 [5]. Conflicting results have been reported regarding association of ocular symptom severity and clinical approach of COVID-19.

First, ophthalmologic reports were limited to the ocular surface; however, uveitis, chorioretinitis, retinal vascular occlusion, retinal microangiopathy, optic neuritis, diplopia, and cranial nerve palsies were reported as the pandemic continued $[6,7]$. While academic research has shown much evidence about COVID-19's ocular involvement, some critical questions still remain unanswered. Even in cases where COVID19 appears to be the only possible etiological factor in patients, the available literature has not been able to describe these findings are directly related to COVID-19 or developed due to systemic complications of COVID-19. Promising results have been reported regarding the existence of SARS Cov-2 nucleic acid in the retina, vitreous, and aqueous humor in postmortem investigations; however, existence of complete

Serdar Ozates

serdarozates@gmail.com

1 Department of Ophthalmology, Okan University School of Medicine, İçemeler Mah. Aydınlı Yolu Cad. No: 2, 34947 Tuzla, Istanbul, Turkey
SARS Cov-2 body and its infectivity in the ocular structures are still unknown $[8,9]$.

In the light of the current literature, assuming COVID-19 as an etiologic factor for ocular disorders without significant proof may cause misdiagnosis and inappropriate treatment. In this case, it would be wise to consider COVID-19 as the underlying factor after ruling out all other possible etiological factors characterized by a similar clinical presentation.

Recently, new mutations of SARS Cov-2 have been announced, and new SARS CoV-2 variants are hypothesized to increase transmissibility [10]. Current literature does not provide information whether new mutations can chance the affinity of SARS Cov-2 to bind to the ocular structures, course of the ocular involvement, or the prevalence of ocular symptoms.

On the other hand, the effectiveness and protection of a global vaccination is still a controversial issue. The impact of vaccination on ocular symptoms and signs will be an attractive topic for future clinical studies. A large proportion of the population should be vaccinated to reliably assess the effect of vaccination on ocular symptoms.

Code availability Not applicable.

Author contribution The first draft of the letter was written by Serdar Ozates, and Basak Bostanci Ceran commented and revised the letter. All authors read and approved the final manuscript.

Data availability Not applicable.

\section{Declarations}

Ethics approval Not applicable.

Consent to participate Not applicable.

Consent for publication Not applicable.

Conflict of interest The authors declare no competing interests. 


\section{References}

1. Gegúndez-Fernández JA, Llovet-Osuna F, Fernández-Vigo JI et al (2021) Recommendations for ophthalmologic practice during the easing of COVID-19 control measures. Acta Ophthalmol. https:// doi.org/10.1111/aos.14752

2. Hattenbach LO, Heinz P, Feltgen $N$ et al (2020) Impacts of the SARS-CoV-2 pandemic on ophthalmic care in Germany. Ophthalmologe. 117(9):892-904. https://doi.org/10.1007/s00347020-01220-4

3. Aggarwal K, Agarwal A, Jaiswal N et al (2020) Ocular surface manifestations of coronavirus disease 2019 (COVID-19): a systematic review and meta-analysis. PloS one. 15(11):e0241661

4. Nasiri N, Sharifi H, Bazrafshan A et al (2021) Ocular manifestations of COVID-19: a systematic review and meta-analysis. J Ophthalmic Vis Res 16(1):103-112. https://doi.org/10.18502/jovr. v16i1.8256

5. Barnett BP, Wahlin K, Krawczyk M et al (2020) Potential of ocular transmission of SARS-CoV-2: a review. Vision (Basel). 4(3). https://doi.org/10.3390/vision4030040
6. Bertoli F, Veritti D, Danese C et al (2020) Ocular findings in COVID-19 patients: a review of direct manifestations and indirect effects on the eye. J Ophthalmol. 2020:4827304

7. Ortiz-Seller A, Martínez Costa L, Hernández-Pons A et al (2020) Ophthalmic and neuro-ophthalmic manifestations of coronavirus disease 2019 (COVID-19). Ocul Immunol Inflamm. 28(8):12851289

8. Casagrande M, Fitzek A, Püschel K et al (2020) Detection of SARS-CoV-2 in human retinal biopsies of deceased COVID-19 patients. Ocul Immunol Inflamm. 28(5):721-725

9. Casagrande M, Fitzek A, Spitzer MS et al (2021) Presence of SARS-CoV-2 RNA in the cornea of viremic patients with COVID-19. JAMA ophthalmology. https://doi.org/10.1001/ jamaophthalmol.2020.6339

10. Leung K, Shum MH, Leung GM et al (2021) Early transmissibility assessment of the N501Y mutant strains of SARS-CoV-2 in the United Kingdom, October to November 2020. Euro Surveill 26(1). https://doi.org/10.2807/1560-7917.Es.2020.26.1.2002106

Publisher's note Springer Nature remains neutral with regard to jurisdictional claims in published maps and institutional affiliations. 